\title{
A Synthesis of Higher Educational Management of Thailand and ASEAN Community
}

\author{
W. Thaima and R. Sanitya
}

\begin{abstract}
The purpose of the research was to synthesize the higher education management of Thailand and ASEAN community by applying the qualitative research method acquired through documentary research. The research tools used were synthesis matrix and content analysis. The results as follows:

1). Vision and administration aspect, ASEAN countries share the vision as representing high quality human resource and a knowledge base. It has been synthesized that Thailand should have a set vision in terms of educational research development and national identity and value preservation.

2). Mechanics and procedure aspect, ASEAN countries identify the same educational management as professional development, curriculum quality, national standard development, ICT in educational management, graduates quality, and higher education's financial reform. The synthesis suggested that Thailand should consider mechanics in terms of improving curriculum, methods, English as a medium and developing curriculum corresponding to $21^{\text {st }}$ century skills.

3). Collaboration of each sector in each country's educational management in Thailand and Malaysia. These countries represent the same point by cooperating with private sectors in educational management. The synthesis stated that Thailand should consider about educational collaboration among ASEAN countries to correspondence with education and training policies.
\end{abstract}

4). Development and problem-solving by researching, ASEAN countries have different educational management frameworks. The synthesis claimed that Thailand should bring up national education evaluation emphasizing on internal evaluation.

5). Educational management support of each country, ASEAN countries share the same supports as higher education foundation, professional resources, and financial supports. The synthesis stated that Thailand should identify teaching professional development.

Index Terms-Educational management, higher education, ASEAN.

\section{INTRODUCTION}

Educational management plays an important role in country and citizenship development to enable the country to be a leading country, for instance, education in South Korea has been raised to be one of the featured policies in economics and social development. The education has been prepared for its citizens as improving the educational system and enhancing life-long learning as it is a famous country in technology [1]. Another example is education reform for $21^{\text {st }}$

Manuscript received November 30, 2015; revised February 29, 2016.

W. Thaima and R. Sanitya are with the Sripatum University, Bangkok Thailand (e-mail: Waraporn.th@spu.ac.th, rugsapon.sa@spu.ac.th). century education which has been employed in the US by announcing Goals: 2000 Educate America Act in 1994 and evaluating the National Education Ministry's policies and plans of 1988-2002. The act aimed to prepare human resources for the future labor market. Recently, the US paid attention to education for nation by providing policies corresponding to $21^{\text {st }}$ century economics. Consequently, some leading countries focus on education as one factor for successful development [2].

In 2015, Southeast Asian countries formed an organization to collaborate on economic, social and educational growth in the region under the name of "ASEAN Community". The vision is that the 2020 ASEAN Community would be harmoniously merged. Even though there would be differences among ASEAN countries, the 2020 ASEAN vision employs education to merge gaps in order to develop its own citizens by promoting education, enhancing life-long learning, creating innovative workshops for careers, supporting people, technology and research [3] each country has prepared as [4] reported that every country in the ASEAN community had focused on education development with the purpose of making it better and also to achieve stronger collaboration among countries corresponding to the vision and missions of ASEAN.

Therefore, to support the education system in the ASEAN community to be global and quality by focusing on academic collaborations (curriculum, research, and academic services) harmoniously, this study aimed to synthesize higher education management in Thailand and ASEAN countries and the findings would be seen as further policy suggestions for higher education management.

\section{OBJECTIVE}

The study aimed to synthesize higher educational management in Thailand and ASEAN countries.

\section{LITERATURE Review}

P. Wasarach (2002) [5] stated that educational management is a systematical process with the aim of human development in every dimension (physical, mental, mind, ethics, values, thoughts, practices and etc.). Educational management has to be a continuous process which includes responsible people and organizations, systematical process, resources, and valid and reliable evaluation.

Office of the Education Council, Thailand (2006) [4] had conducted a comparative study about education reforms among ASEAN countries by document analysis and interview those whom it concerned. The study employed content 
analysis to create suggestions for Thailand as education collaboration strategies. The findings are 1) every country in ASEAN focuses on education development as reforming education regulations and policies by announcing education regulations and merging education development plans in a national economic and social development act. This act includes basic education development plan, vocation education development plan, higher education development plan, and operational plans in educational service areas and schools. The main idea of the education development plan is to lead the society to be a society of knowledge which will be reached as a knowledge-based economy when every citizen can make use of the acquired knowledge. 2) There is a common trend on the reform of higher education in each country which is to expand education opportunity and to enhance education quality as to 1) be a knowledge-based society, 2) form global education, 3) correspond with economic and social development both nationally and locally, 4) enhance economic competition, and 5) develop human resources. 3) Suggestions concerning Thailand's role in education collaboration as 1) Thailand should promote academic support concerning vision and missions of ASEAN in the form of partnerships with other organizations. 2) Thailand should promote a knowledge-based society and leadership society in order to enhance research and the identity of the ASEAN community. It could be achieved by promoting basic education quality to be the best root for higher education. To promote higher education in teaching, learning, and researching needs various collaborations; policy making, planning, research and development, education development in related organizations as basic education and higher education.

According to the suggestions, it leads to synthesis of higher education management in Thailand and the ASEAN community as referring to further national policy suggestions.

\section{Methodology}

The study employed qualitative research as document analysis to collect data from the 10 ASEAN countries: Indonesia, Malaysia, the Philippines, Singapore, Brunei, Vietnam, Laos, Myanmar, Cambodia and Thailand.

The data is related to higher education management and the documents include education reports, research and articles which covers five aspects; 1) Vision and administration aspect which implies needs and goals of each national educational management in the ASEAN community, 2) Mechanics and procedure aspect which indicates process, methods, and steps of educational management in the ASEAN community, 3) Collaboration of each sector in national education management among the ASEAN community which portrays collaboration towards educational management as policy making, planning, and operating, 4) Development and problem-solving by using research which would make use of research findings to develop and solve educational management issues in the ASEAN community, and 5) Educational supports related to resources and budgets which would support education management in order to achieve the goals.
The source of documents for a synthesis were from the Ministry of Education website, International Bureau of Education website, Thai Library Integrated System, library, etc. The documents were selected carefully based on 1) reliability and 2) published period; from 2010-2015. As a result, there were 30 of 52 documents to be analyzed by content analysis.

\section{RESULTS}

The synthesis of higher educational management in Thailand and ASEAN countries has been divided into five aspects as follows:

\section{A. Vision and Administration Aspect}

\section{1) Concurrences}

Thailand and ASEAN countries have shared a concurrent point of vision and administration in educational management as a high quality resource of human development and a quality knowledge base. Moreover, Thailand has shared some points with some ASEAN countries such as sharing life-long learning vision with Myanmar, sharing professional development vision with Vietnam and sharing global education development vision with Singapore. (Fig. 1)

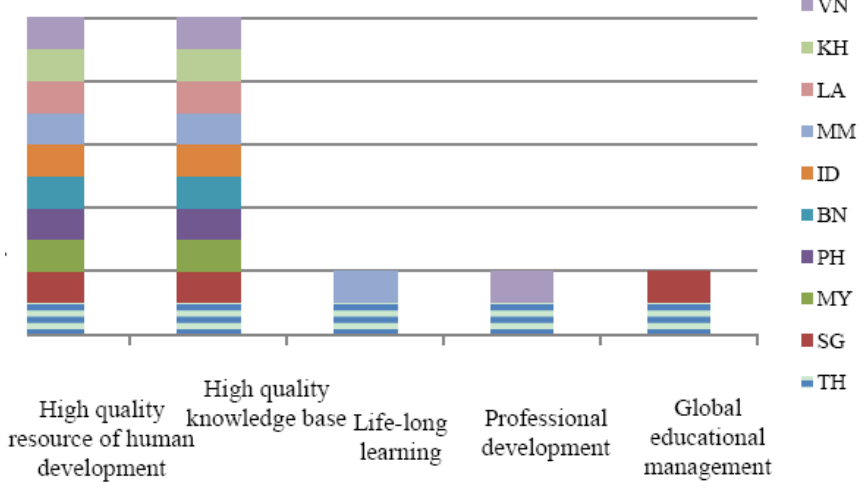

Fig. 1. Concurrent points of educational management in vision and administration aspect of Thailand and ASEAN countries.

\section{2) Differences}

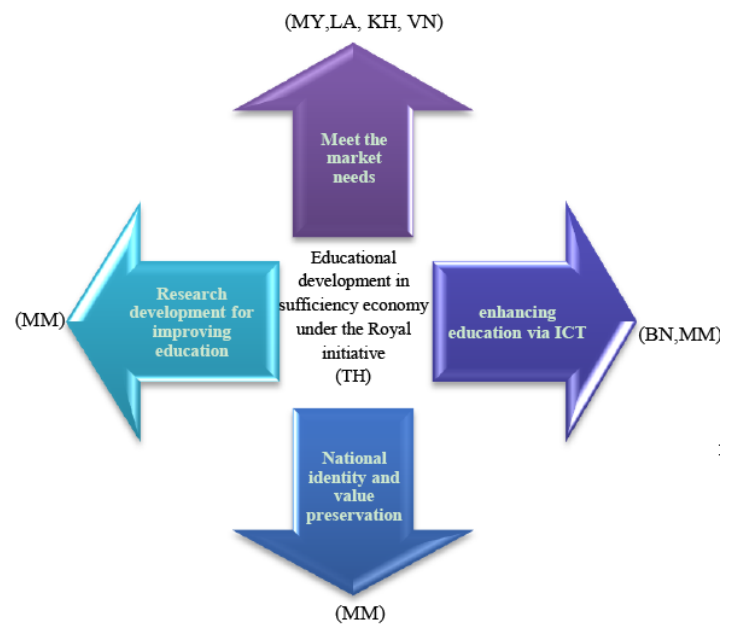

Fig. 2. Different point of educational management in vision and administration aspect of Thailand and ASEAN countries.

ASEAN countries such as Malaysia, Laos, Cambodia and Vietnam have set higher education visions and administration 
in order to meet the market needs such as applying technology in education. Brunei has focused on e-learning as one of its national strategies, also Myanmar has promoted ICT to enhance educational management. Besides, Myanmar has defined national identity and value preservation vision and also research development vision for higher education. In addition, Thailand has appointed education in sufficiency economy under the Royal Initiative which is unique from other countries' visions (Fig. 2).

As a result, Thailand should consider issues on research development for better education and identity and value preservation to be national visions and administrations since one of the Thai higher education visions is education development according to sufficiency economy under the Royal Initiative. This development needs support from research and national identity and value preservation for further educational development.

\section{B. Mechanics and Procedure Aspect}

\section{1) Concurrences}

Thailand and ASEAN countries have shared a concurrent point of mechanics and procedure aspect in higher education management as professional development. This is the concurrent point among Indonesia, Myanmar, Laos and Vietnam such as holding professional workshops and recruiting $\mathrm{PhD}$ lecturers. Moreover, it was found that the graduate quality needed improving in order to meet a labor market need which is the shared vision of Thailand, Laos, and Vietnam. Thailand and Singapore contribute financial reform aspect to drive higher education to be the best.

Improving curriculum quality and the standard national education framework are the issues which Thailand, Singapore, Myanmar and Laos emphasize to be one of the educational management mechanics. Further, Thailand, Malaysia and Myanmar have set ICT usage such as to share information for educational management. The last issue which Thailand has shared with Indonesia and Myanmar is educational collaboration among the region (Fig. 3).

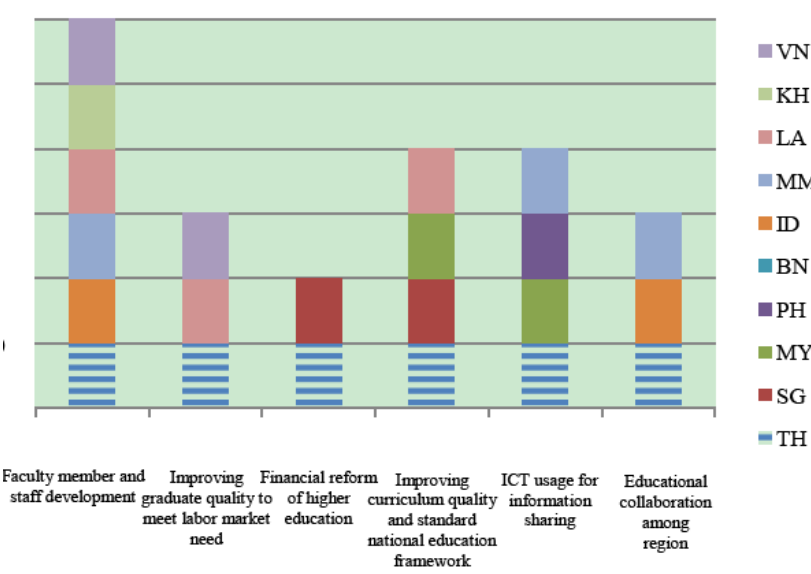

Fig. 3. Concurrent point of educational management in mechanics and procedure aspect of Thailand and ASEAN countries.

\section{2) Differences}

It was found that Singapore and Vietnam are working on this aspect effectively such as increasing foreign student enrollment rate and founding international universities. Additionally, Singapore also emphasizes on internal quality assurance. Moreover, Malaysia and Brunei have planned to improve curriculum, teaching methods and using English as a medium in accordance with $21^{\text {st }}$ century issue. In contrast, these two issues were not found in the Thailand policy. The Philippines is the only country that has merged education of disaster management in a national education policy. (Fig. 4)

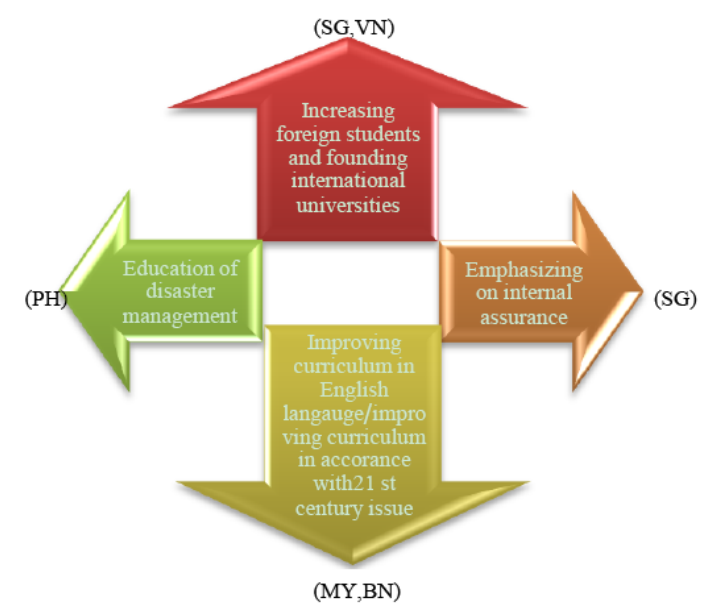

Fig. 4. Different point of educational management in mechanics and procedure aspect of Thailand and ASEAN countries.

According to the findings above, Thailand should consider the issues of improving its curriculum, teaching methods, using English as a medium in accordance with $21^{\text {st }}$ century issue and emphasizing internal quality assurance, however, these aspects should be considered under the vision and administration aspect.

\section{Collaboration of Each Sector in Educational Management Aspect}

\section{1) Concurrences}

The finding shows that only Thailand and Malaysia have shared this aspect as private sectors are allowed to collaborate in terms of administration and management in higher education (Fig. 5).

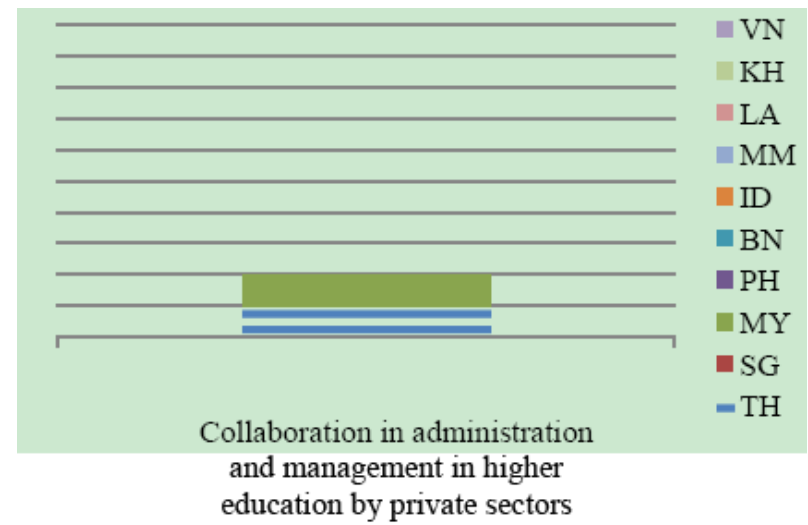

Fig. 5. Concurrent point of educational management in the collaboration of various sectors in Thailand and ASEAN countries.

\section{2) Differences}

Thailand obviously raises educational collaboration among various sectors according to the Higher Education Development Plan Vol. 11 (2012-2016) of which the collaboration between universities and the private sector has been set as teaching, learning, researching and operating. Further, Singapore has centralized its administration and 
Myanmar has prepared education collaboration with many universities in ASEAN and overseas (Fig. 6).

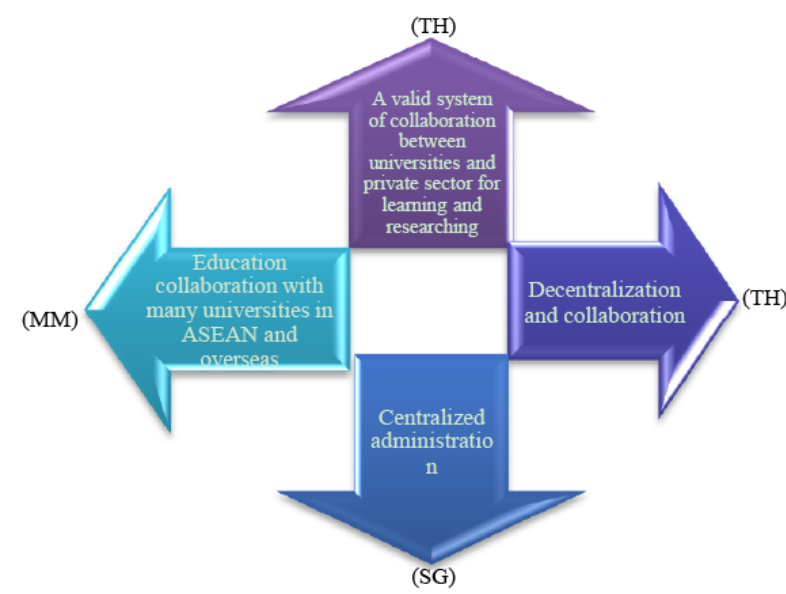

Fig. 6. Different point of educational management in the collaboration aspect of Thailand and ASEAN countries.

To appoint a guideline on education collaboration among ASEAN and Thailand, the collaboration issue should be set in accordance with education and training free policy.

\section{Development and Problem-Solving by Researching Aspect}

According to the synthesis, concurrence in this aspect was not found, yet there was an interesting point in this synthesis which was Thailand has focused on professional development in research skills whereas Myanmar and Vietnam has emphasized on research skills development to enhance education quality and to meet the private sector and entrepreneur needs.

Singapore pays attention on assessment such as it appoints internal assurance in schools and institutions. This issue has not been found in other ASEAN countries (Fig. 7).

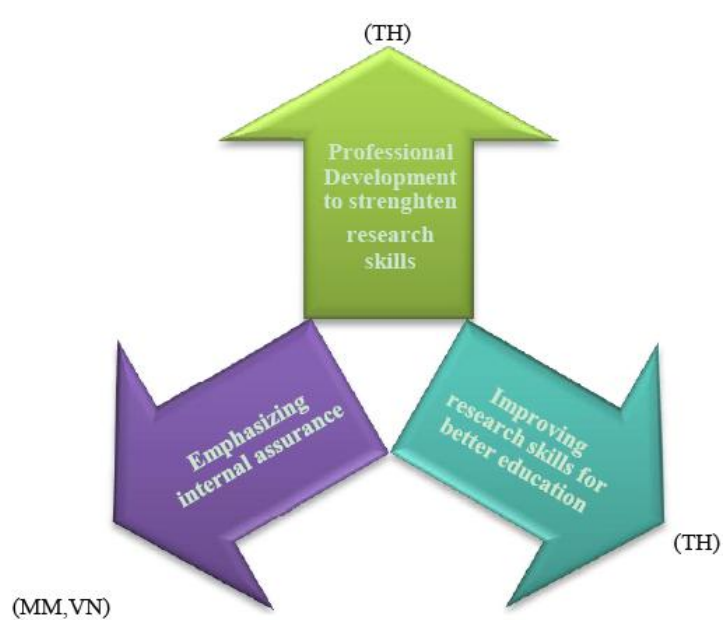

Fig. 7. Different point of educational management in development and problem-solving by researching aspect of Thailand and ASEAN.

Thailand should consider adapting assessment by focusing on internal assurance such as education institutions would understand and improve themselves.

\section{E. Educational Management Supports Aspect}

\section{1) Concurrences}

Thailand, the Philippines, Myanmar, and Laos have shared a point of educational management supports as to improve basic infrastructure of information technology and ICT for educational management. To recruit university lecturers or officers, Thailand and Vietnam have shared this issue to meet the labor market needs.

Thailand and Singapore have the concurrent point such as increasing educational scholarships and distributing scholarships to people in need for a better human resource (Fig. 8).

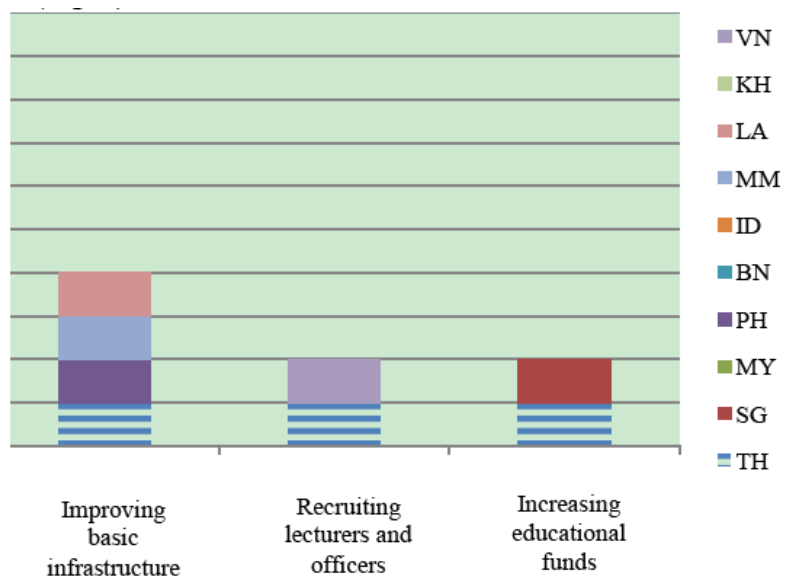

Fig. 8. Concurrent point of educational management in educational management supports in Thailand and ASEAN countries.

\section{2) Differences}

Besides Thailand appointing the recruitment of university lecturers to meet its needs, educational management support is appointed also by reconsidering salary rate. In contrast, this point has not been found in other ASEAN countries. Singapore and Cambodia have supported educational management by developing their human resources. Vietnam has founded international universities to support the country (Fig. 9).

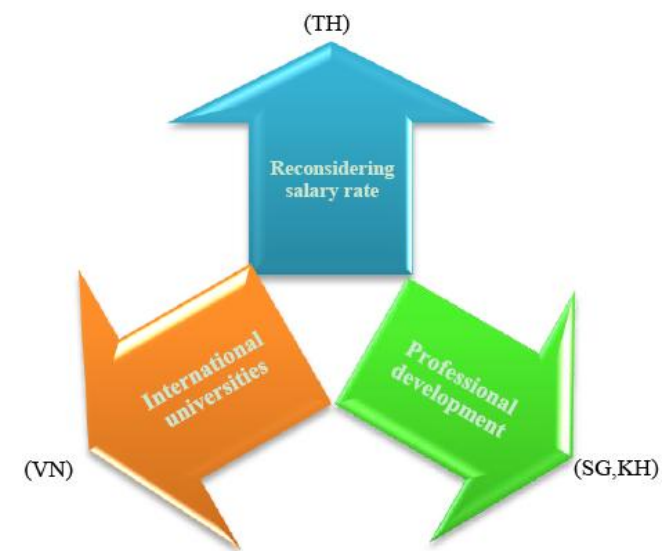

Fig. 9. Different point of educational development in educational development supports of Thailand and ASEAN countries.

Thailand should think about having professional development in order to enhance lecturers to be more professional and effective in accordance with the national policy.

\section{DISCUSSION}

The findings were 1) Vision and administration aspect, Thailand and ASEAN share the vision as representing high quality human resource and a knowledge base, 2) Mechanics 
and procedure aspect, Thailand and ASEAN countries identify the same educational management as professional development, curriculum quality, national standard development, ICT in educational management, graduates quality, regional education collaboration and higher education's financial reform. This is according to a study from the Office of the Educational Council [4], 2006 which conducted a comparative study about education reforms among ASEAN countries by document analysis of which was found that every country in the ASEAN community emphasizes on improving education quality such as regulations and policy which lead the society to be a society of knowledge which will be reached as a knowledge-based economy when every citizen can make use of the acquired knowledge for better lives, 3) There is a common trend on the reform of higher education in each country which is to expand education opportunity and to enhance education quality as to 1. be a knowledge-based society, 2. form global education, 3 . correspond with economic and social development both nationally and locally, 4 . enhance economic competition, and 5. develop human resources. The findings go along well with a study by W. Thaima and others [6] in Strategies for Developing the Educational Quality for the Institutions of Higher Education in Thailand for ASEAN Students. The study aimed to explore background information of ASEAN students whom study in Thailand and to set national higher education development strategies. The studied data is secondary sources taken from the Higher Education Committee Office and experts who have worked on administration. The findings of higher education development strategies are 1) developing higher education management quality, 2) appointing professional development, and 3) strengthening academic performance.

Moreover, it was found that improving basic infrastructure of higher education information, recruiting lecturers, and increasing education funds are the concurrent point in supporting educational management aspect as L. Petchroj [7] stated that educational management strategies of private higher education institutions. The aims of this study were 1) to study educational management strategies of higher education institutions, 2) to study main elements of important educational management strategies and indicators, and 3) to suggest ways for managing education in private higher education institutions. The data was taken from administrators, lecturers, and officers in private higher education institutions. The findings were six main elements of educational management strategy such as 1) research collaborations in learning about the ASEAN community, 2) various informative channels, 3) basic infrastructure development and communication for the improvement of lecturers and officers, 4) awareness in cultural differences, 5) ASEAN education policy making, and 6) being part of a developing country. Therefore, the aspect of the private sectors' collaboration in educational management, it was found that Thailand and Malaysia shared the same point as stated in the Higher Education Development Plan vol.11 (2012-2016) [8] which encouraged the private sector to be part of higher education development in terms of planning in administration management.
However, Thailand should consider the following aspects for the next plan such as 1) vision and administration aspect; research quality development for better education issue and national identity and value preservation issue, 2) Mechanics and procedure aspect; developing/improving curriculum, teaching methods, using English as a medium in accordance with $21^{\text {st }}$ century issue, 3 ) collaboration of each sector in educational management; collaboration appointment among ASEAN countries in accordance with education and training free policy, 4) development and problem-solving by researching aspect; focusing on internal assurance as education institutions would understand and improve themselves, and 5) educational management supports aspect; having professional development in order to enhance lecturers to be more professional and effective.

\section{REFERENCES}

[1] T. Wongvesetkul. (March 2014). Unraveling the secrets of creating Korean in Asian. [Online]. Available: https://www.thairath.co.th/content/life/195753

[2] Office of the Educational Council, The Decentralization of Education in the United States, Bangkok: Office of the Educational Council, 2007.

[3] P. Ratakul. “ASEAN story,” Higher Educational Journal, pp. 7-11, April 2012.

[4] Office of the Educational Council, Comparative Research in Education Reform in ASEAN Countries, Bangkok: Office of the Educational Council, 2006.

[5] P. Wasarach. (September 2015). Executive Training Supplementary. [Online]. Available: http://suthep.crru.ac.th/book6/1.pdf. 2002

[6] W. Thaima et al., "Strategies for developing the educational quality for the institutions of higher education in Thailand for ASEAN students," in Proc. 2015 APHEIT Conf. 2015, pp. 66-80.

[7] L. Petchroj, Steategies for Higher Education Management of Thai Private Educational Institutions towards ASEAN Community, Rajapruk University: Nonthaburi, 2013.

[8] Office of Higher Education Commission, Higher Educational Plan Issue No. 11. 1992-1996, Chulalongkorn University Press, Bangkok.

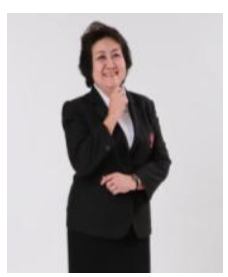

W. Thaima was born in Bangkok, Thailand on September 28, 1955. Her educational background is a doctor of education program in administrative and policy studies, University of Pittsburgh, Pennsylvania, USA in 2000, a master of science degree program in business education from New Hampshire College, New Hampshire, USA in 1993 and a bachelor of arts degree program in English, Suan Sunandha Teachers' College in 1982. She worked as an acting director in Sripatum Institute of Languages and Cultures, Sripatum University, Bangkok, Thailand from 2015 to present, as the director, doctor of philosophy program in educational administration, Graduate College of Management, Sripatum University, Bangkok, Thailand from 2009 to present. From 2011 to 2013, she worked as an assistant dean for academic Affairs, faculty of liberal arts, Sripatum University, Bangkok, Thailand, etc. she published some articles.

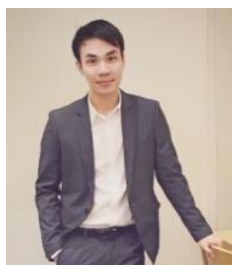

R. Sanitya was born in Nan province, Thailand, on May 23, 1987. For educational background is the master degree in demography, College of Population Studies, Chulalongkorn University, Bangkok Thailand in 2012 and the bachelor degree in social research, the Faculty of Social Science, Naresuan University, Thailand in 2009. He worked as a researcher of Teaching and Learning Support and Development Center, Sripatum University, Bangkok Thailand from 2015 to present. In 2013, he worked as a research assistant of the understanding social barriers to coping with and adapting to extreme climate events project, College of Population Studies, Chulalongkorn University Thailand. 